\title{
Imagens de uma língua: reflexões sobre o ensino de alemão como língua estrangeira no Brasil
}

\author{
Ruth Bohunovsky*
}

\begin{abstract}
In the theoretical context of Critical Applied Linguistics, this paper examines two aspects that are important for a consideration of the possible imaginaries that permeate the contact between a Brazilian student and German as a foreign language. I analyze the possible consequences of the argument that German is a very "cultivated" and difficult language, as well as the lack of incentive, in didactic material, for reflections on the peculiarities of a possible contact between a Brazilian student and the German language or a native speaker of that language. Finally, this paper intends to discuss whether if there is any didactic material used for teaching of German in Brazil which stimulates the pupils to criticize the peculiarities and the imaginaries that permeate their contact with the German culture and language.
\end{abstract}

Keywords: Critical Applied Linguistics; Teaching of German as a Foreign Language in Brazil; Discourse; Ideology,

Zusammenfassung: Ausgehend von den theoretischen Grundlagen der Angewandten Kritischen Linguistik werden zwei für den Unterricht des Deutschen

\footnotetext{
A autora é pós-doutoranda no Instituto de Estudos da Linguagem (IEL), na Universidade Estadual de Campinas (UNICAMP), na área de Lingüística Aplicada, sob supervisão da Profa. Dra. Carmen Zink Bolognini, financiada pela FAPESP (processo nr. 03/13796-6).
} 


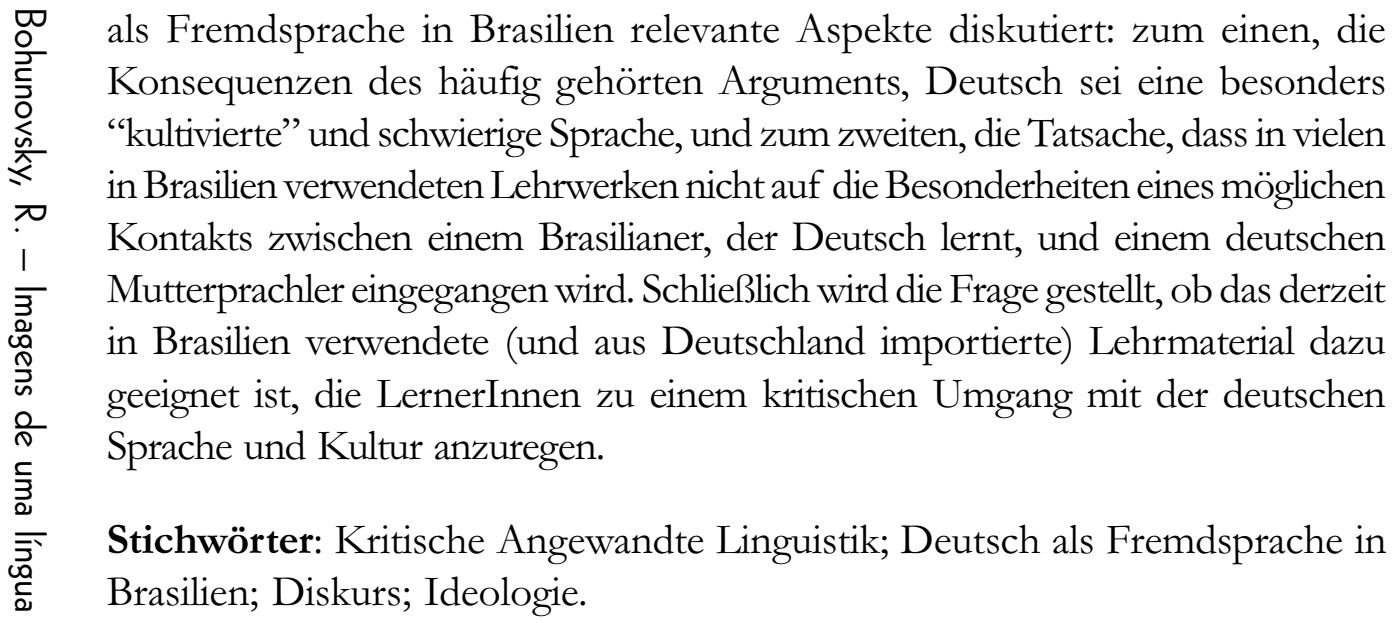

Palavras-chave: Lingüística Aplicada Crítica; ensino de alemão no Brasil; discurso; ideologia.

\section{Introdução}

No contexto da teoria cultural pós-estruturalista, da Lingüística Crítica (Fairclough 1995) e da Lingüística Aplicada Crítica (Pennycook 1999; 2003), tem havido reflexões constantes sobre conceitos como discurso, ideologia e imaginário, considerados componentes não só das salas de aula, mas também dos próprios materiais didáticos. Neste âmbito teórico, partese de uma concepção teórica que enfoca o caráter constitutivo da linguagem. Uma das premissas mais importantes dessas abordagens para o ensino de uma língua estrangeira é a de que, ao aprender uma nova língua, o sujeito não adquire simplesmente um novo modo de se comunicar, mas entra em contato com novas ideologias, novos discursos, outras maneiras de significar o mundo. Essa visão trouxe conseqüências para todas as facetas do ensino de língua estrangeira.

No presente trabalho, propõe-se uma discussão crítica sobre o imaginário acerca da língua e da cultura alemãs, especificamente no Brasil. A partir disso, discute-se se o material didático utilizado no ensino de alemão como língua estrangeira pode contribuir para aumentar, estabilizar ou questionar esse imaginário - e, consequentemente, se o material didático atual- 
mente utilizado no Brasil para o ensino de alemão é adequado para estimular os aprendizes dessa língua a desenvolverem um olhar mais crítico e atento acerca o referido imaginário.

\section{Ideologia e discurso na Lingüística (Aplicada) Crítica}

O conceito de ideologia utilizado por teóricos como Pennycook ou Fairclough não deve ser compreendido conforme a tradição epistemológica que relaciona a ideologia a idéias como ilusão, distorção ou mistificação de uma suposta realidade (p. ex., Gottfried W. F. Hegel, Karl Marx, George Lúkacs), nem conforme a tradição sociológica que se interessa pela função das idéias na vida social (cf. EAGLETON 1997: 16). No contexto referido neste trabalho, deve-se entender ideologia como "os modos pelos quais o significado (ou a significação) contribui para se manterem as relações de dominação" (Thompson 1984, apud Eagleton 1997: 19). Eni P. Orlandi (1990: 36) oferece uma definição bastante esclarecedora para a discussão aqui apresentada: de acordo com essa teórica, a ideologia seria "a direção nos processos de significação" e "se sustenta[ria] no fato de que o imaginário que institui as relações discursivas é político". É relevante mencionar que, nessa linha de pensamento, a ideologia é vista como algo que não apenas determina a "grande" política e nossa visão de mundo, mas também nossas relações sociais quotidianas.

Com respeito ao conceito de discurso - estreitamente ligado ao de ideologia, sigo aqui a definição de FAIRCLOUGH. Segundo esse lingüista crítico, o discurso seria uma "prática social" (1995: 63) e representaria uma "relação ativa com a realidade" (1995: 42), constituindo os "objetos do conhecimento, os sujeitos sociais", as formas do "eu" e as "relações sociais" (1995: 39). Há discursos estabilizados institucionalmente, como o discurso jornalístico, o científico, o publicitário etc.; e há discursos menos formais como, por exemplo, o discurso feminista, o discurso racista ou o colonial. Nenhum desses discursos funciona por si só, mas significa no contato, confronto e entrecruzamento com outros. Usando as palavras de FAIrClOUGH, as práticas discursivas não só contribuem para "reproduzir a sociedade como ela está", como também podem "contribuir para transformar a sociedade" (1995: 65). Ou seja, o discurso não apenas reflete a suposta realidade extralingüística, as relações de poder e de domínio político, 
mas pode também exercer um papel ativo em eventuais mudanças dessas estruturas ${ }^{1}$.

A partir dessa compreensão de ideologia e discurso surgiram algumas reflexões sobre as implicações desses conceitos para o ensino. Como já argumenta Michel Foucault, "qualquer sistema de educação é uma maneira política para manter ou mudar as apropriações dos discursos, junto com o conhecimento e o poder que eles envolvem" (FAIRCLOUGH 1995: 51). Isso implica que a sala de aula seja um lugar de grande relevância nesse processo, seja para manter, seja para mudar essas apropriações. A sala de aula é o lugar onde, com ou sem o conhecimento e o consentimento do professor, um determinado discurso e uma ideologia dominante poderiam se fixar ainda mais, ajudando a estabilizar um determinado poder. Tanto para os aprendizes quanto para os professores, os discursos e suas ideologias podem aparecer como naturalizadas, como naturais, uma vez que a naturalização ou universalização de crenças com um fim de torná-las “óbvias e aparentemente inevitáveis” (EAGLETON 1997: 19) é exatamente uma das estratégias da ideologia para se manter dominante. No entanto, ainda assim, a sala de aula seria o lugar onde a conscientização, e até a mudança, desses discursos pode acontecer. Nesse sentido, partindo do pensamento de Paulo Freire, Henry Giroux (apud: Rajagopalan 2003: 105) argumenta que

ensinar, nos termos de Freire, não é simplesmente estar em sala de aula, mas estar na história, na esfera mais ampla de um imaginário político que oferece aos educadores a oportunidade de uma enorme coleção de campos para mobilizar conhecimentos e desejos que podem levar a mudanças significativas na minimalização do grau de opressão na vida das pessoas.

Um ponto comum às diversas abordagens dentro do contexto teórico acima mencionado é o interesse no caráter crítico das discussões acerca do

1 Na questão do grau de atividade e criatividade do discurso em relação à "realidade extralingüística", Fairclough - que, no geral, parte do pensamento foucaultiano - se afasta criticamente da linha de argumentação do filósofo francês. FAIRCLOUgh (1995: 56) observa que Foucault "exagera na extensão na qual a maioria das pessoas é manipulada pelo poder" e pelo discurso. Ou seja, FAIRCLOUGH atribui ao sujeito um papel mais ativo que Foucault. 
ensino de línguas estrangeiras. Entende-se por "crítico" a tentativa de "mostrar relações e causas que estão escondidas" (FAIRCLOUGH 1995: 9) ou, usando as palavras de PENNYCOOK (2003: 26) ao referir-se explicitamente ao ensino, "entender as relações entre conceitos de sociedade, ideologia, capitalismo global, colonialismo, educação, gênero, racismo, sexualidade, classe e os discursos da sala de aula." O fato de se denominar a obra de um autor como possuidora de um caráter "crítico" revela também que a sua postura é bem mais aberta à intervenção política do que aquela comum nas últimas décadas. A adoção de um caráter crítico na Lingüística Aplicada vai implicar uma postura "politicamente mais responsável" (2003: 28), visando oferecer aos aprendizes não apenas informações sobre o contexto sociocultural, político, ideológico e histórico do(s) país(es) da língua-alvo e dos seus falantes, mas também encorajá-los a desenvolver um olhar mais crítico em relação aos imaginários já “naturalizados” (2003: 29) em favor de uma certa ideologia. Como aponta Pennycook, a Lingüística Aplicada Crítica está em constante diálogo com outros campos acadêmicos como a teoria crítica, o feminismo, o pós-colonialismo, o pós-estruturalismo e a pedagogia antiracista (2003: 31), abrindo assim "um novo leque de questões e considerações", em que temas como "identidade", ou "a reprodução daquilo que caracteriza o Outro", que "até agora não [tinham] sido considerados como pertinentes à Lingüística Aplicada" (2003: 31), passam a ocupar um lugar de destaque.

Se, para os teóricos que partem de uma postura crítica, o aspecto político do trabalho de ensino de uma língua estrangeira deve ser considerado pelos profissionais dessa área, isso valeria também para o material didático. Assim como toda linguagem escrita ou falada, esse material é entremeado por vários discursos marcados política e ideologicamente, mesmo que os autores e os leitores não estejam conscientes disso. É pertinente mencionar que, no âmbito da Lingüística Aplicada Crítica, há uma crescente quantidade de análises críticas sobre os interesses e as ideologias inerentes à construção e à interpretação de livros didáticos (cf. PennyCoOK 2003: 40).

Partindo da premissa de que linguagem não é - e nem pode ser apenas um meio para a transmissão de informações ou para a mera comunicação, a idéia tradicional de que o ensino de uma língua estrangeira possa ser apenas o ensino de uma outra "forma" para o mesmo conteúdo 
lingüístico perdeu sua validade. Fala-se, muito mais, em "redefinição cultural" (Rajagopalan 2003: 70), pois o contato com uma outra língua traz sempre também o contato com uma outra cultura, com outras formações discursivas, outras ideologias e imaginários, inseparavelmente ligados à língua em si. Nesse contato, nossas identidades são submetidas a um processo de reformulação e de constante transformação, nós nos transformamos em outras pessoas (2003: 70). Esse processo pode se dar de maneira inconsciente. Mas, no âmbito do pensamento crítico, defende-se, cada vez mais, que os alunos sejam levados a refletir sobre essa carga ideológica que envolve qualquer contato entre duas línguas e culturas. Ou seja, visa-se a estimular os aprendizes a atentarem para os diversos discursos heterogêneos que necessariamente vão marcar o contato que eles estabelecerão com uma outra língua e seus falantes - discursos com maior ou menor poder político e com embasamentos ideológicos e interesses diferentes.

\section{Imaginários}

Olhando para os imaginários que têm marcado, por um lado, o Brasil e, por outro, os países de língua alemã nos últimos séculos, não se pode negar a importância do discurso colonial para ambos os lados - embora de maneiras opostas. Enquanto o fato de ter sido colônia sempre marcou o imaginário do Brasil e dos brasileiros acerca deles mesmos (o que não significa que esse imaginário, ou "a identidade brasileira", seja algo estável e fixo), os países de língua alemã adotaram muito mais o discurso do colonizador. Isso fica claro, por exemplo, na afirmação de Celeste H. M. R. Sousa acerca das perspectivas literárias que teriam marcado as relações Alemanha - Brasil nos últimos séculos. Como argumenta Sousa (1996: 211), existiriam “duas perspectivas distintas” acerca do Brasil. A primeira consideraria esse país e a Alemanha como "realidades idênticas", negando ao Brasil sua "especificidade". Já a segunda perspectiva entenderia os dois referidos países em termos de "superioridade" e "inferioridade", o que redundaria, novamente, em um etnocentrismo (1996: 211). A autora conclui que "a imagem do Brasil, em essência, ainda se encontra vinculada a fantasias referentes ao continente recém-descoberto, isto é, a mitos da Conquista” (1996: 211). Pode-se resumir que tanto a universalização quanto a hierarquização de 
valores apresentam-se como provenientes do discurso colonial - que sempre é um discurso de cima para baixo: ou todos são, no fundo, iguais ou o outro é inferior.

Essa avaliação do imaginário em relação ao Brasil está em consonância com a argumentação desenvolvida por Eni P. ORLANDI (1990), que defende que o discurso historiográfico europeu - que foi assumido em grande parte também pelo pensamento brasileiro - teria concedido a esse país apenas a posição de uma cópia da Europa que, com mais ou menos sucesso, teria conseguido se aproximar do seu "ideal". Ou seja, o Brasil nunca teria sido muito mais do que uma parte da história européia, os sentidos produzidos acerca desse país teriam favorecido a manutenção das relações hierárquicas entre a (ex)colônia e a Europa. Conseqüentemente, aos brasileiros tem sido concedido apenas o direito de ter "particularidades, singularidades e peculiaridades culturais" (ORLANDI 1990: 15), mas não uma história própria, uma interpretação peculiar da História.

A validade do discurso colonial começou a ser repensada no contexto do pós-colonialismo - que trouxe a tentativa de descompor a hierarquia de culturas "superiores" e "inferiores", de politizar a estética e a cultura e de visibilizar os mecanismos de demonstração de poder nas imagens e falas coloniais. $\mathrm{Na}$ Lingüística Aplicada Crítica, o foco dessas discussões tem sido os discursos sobre a sala de aula e os que ocorrem durante as próprias aulas.s

\section{A "dificuldade" do alemão como um meio para manter um imaginário hierárquico}

Há muito tempo, a língua alemã tem sido apresentada para o mundo como uma língua de "cultura" (essa concepção é proposta inclusive pela política oficial alemã através de documentos do Ministério das Relações Exteriores). E não é apenas no Brasil que o alemão tem a fama de ser uma língua "culta", "exata" e difícill. Esses adjetivos reforçam a visão da suposta supe-

2 Para uma discussão crítica sobre os argumentos "pré-científicos" que atribuem à língua alemã um elevado grau de complexidade e dificuldade, cf. Ulrich BAUER (2003). 
rioridade não só da língua, mas também da cultura alemã. A suposta impenetrabilidade do universo lingüístico alemão assegura prestígio a quem tiver "conseguido" aprender essa língua fazendo com que este seja visto como uma pessoa culta e distinta. Para se refletir sobre o papel da língua alemã no Brasil, pode-se citar aqui uma observação de Rajagopalan sobre as línguas estrangeiras em geral:

A palavra "estrangeira" é comumente reservada para qualificar uma outra língua que conta com maior respeitabilidade que a língua materna de quem fala (RAjagopalan 2003: 65).

Porém, ao mesmo tempo em que o "domínio" do idioma alemão traz um certo prestígio para o falante, a atribuição de um suposto caráter culto e superior à língua alemã reforça implicitamente uma suposta posição de inferioridade tanto da língua quanto da cultura do brasileiro que estuda aquele idioma. $\mathrm{O}$ interesse em mudar essa situação parece ser pequeno, já que ela é conveniente para manter a posição de "superioridade" de quem já é falante de alemão. Nas palavras de Ulrich BAUER,

a idéia de que a língua alemã seja difícil é cultivada com muito fervor por aqueles que se consideram bons falantes de alemão. Lamentavelmente, muitas vezes trata-se de um comportamento dos próprios agentes culturais alemães no exterior. Quem consegue convencer a todos os outros de que até o "verdadeiro domínio" do alemão há um longo caminho pode mais facilmente sentir-se competente e avançado, ou seja, dono de uma grande cultura intelectual (BAUER 2003: 4).

Como aponta Bauer, essa idéia de que a língua seja um meio para a ascensão social foi durante muito tempo uma das estratégias com as quais os Bildungsbürger - os burgueses alemães com boa educação - se distinguiam em relação às classes inferiores (BAUER 2003: 4). O desenvolvimento de conceitos alemães clássicos como Kultur e Bildung contribuíram nesse processo e levaram à idéia atual de o alemão ser uma língua altamente complexa e repleta de diferenciações detalhadas (2003: 4). Como afirma BAUER (2003: 4), continuando sua argumentação, 
quase não há nenhuma palestra num Instituto Goethe ou num departamento de alemão em alguma universidade do México, e certamente também em outros lugares na América Latina, sem uma das citações obrigatórias de observações polêmicas de Mark Twain sobre o caráter extremamente difícil do alemão (cf. Twain 1985).

Certamente, não há mais ninguém que hoje defenda abertamente uma suposta "superioridade" de uma língua ou cultura em relação a outras, já que o policiamento imposto pelo "politicamente correto" impede tal explicitação. Citando BAUER mais uma vez, às exposições sobre o suposto caráter difícil do alemão seguem regularmente observações como "é divertido estudar alemão" ou "não será tão ruim assim" (2003: 4). Essas declarações são definidas por BAUER (2003: 4) como "contraproducentes", já que não conseguem - nem teriam a intenção - de realmente contradizer o dito acima. Marcado por esse discurso em relação à língua alemã, o aprendiz já inicia a primeira aula na convicção da grande dificuldade que terá de enfrentar para se aproximar do alemão. Assim, segundo uma pesquisa feita por Luciano Lima TAVARES (2000: 525), a conotação mais citada (26,5 \%) dentro de um universo de 200 questionados em relação à língua alemã é "difícil", $11,4 \%$ consideram essa língua "interessante" e "austera", e mais $9 \%$ "complicada".

No seu trabalho, BAuER (2003: 5) pergunta por que os alemães continuam reforçando a idéia da dificuldade de sua língua. De acordo com o autor, um francês iniciaria uma palestra abordando a beleza do francês, um inglês apontaria a importância da sua língua (2003: 5). É possível supor que as três estratégias sirvam para corroborar um suposto caráter superior das três línguas. Assim como a "beleza" do francês e a "importância" do inglês, a "dificuldade" do alemão ajuda a manter imaginários que atribuem a essas três línguas um suposto nível superior em comparação com outras.

Levando em conta os argumentos expostos até aqui, pode-se questionar se o discurso dominante de que o alemão seja uma língua mais difícil e mais "culta" que outras não contribuiria para se manter os imaginários que têm marcado as relações Brasil - Alemanha durante os últimos séculos - ainda que o discurso "oficial” das instituições do ensino de alemão já tenha mudado. 


\section{A questão do outro no material didático para o ensino de alemão}

Para o ensino de alemão como língua estrangeira no Brasil, quase não existe, atualmente, material didático produzido neste país e elaborado especialmente para o aprendiz brasileiro. Geralmente, são utilizados livros didáticos importados da Alemanha que foram produzidos para o ensino de alemão como segunda língua num dos países de língua alemã. Ou seja, o aprendiz brasileiro que estuda a língua alemã se aproxima dessa língua com base num livro feito para um público-alvo do qual não faz parte. Como não poderia ser diferente, esses livros, em momento algum, se propõem a levar em conta especificamente o aprendiz brasileiro ou temas que poderiam ser de interesse para ele. A discussão proposta neste trabalho não deve, portanto, ser entendida como uma "cobrança" de algo que esses livros não pretendem fazer. O que está em questão são apenas as possíveis implicações que o uso desse material traz consigo quando aplicado ao ensino de alemão no Brasil. É relevante mencionar ainda que, além dos livros didáticos citados neste trabalho, há outros sendo usados atualmente para o ensino de alemão no Brasil (por exemplo, Eurolingua, Tangram, Delfin) e muitos deles já consideram as recomendações do Gemeinsame Referenærabmen. Além disso, do ponto de vista didático, eles levam em consideração também as últimas tendências teóricas. No entanto, esse fato não põe em xeque a argumentação apresentada aqui - que se refere apenas ao fato de se usar livros importados que não oferecem (e nem podem oferecer) uma base para uma reflexão crítica de uma possível relação entre um brasileiro, a língua e a cultura alemãs e os falantes nativos de alemão.

Especificamente em relação ao material de ensino de alemão como língua estrangeira quem deu início à discussão sobre os aspectos ideológicos desses textos foi Carmen Zink Bolognini (1996: 174-178) - pelo menos no contexto acadêmico brasileiro. Orientando-se pela análise de discurso de linha francesa ${ }^{3}$, a autora discute o livro Themen Neu e defende que esse material didático ajuda a manter, estabilizar e silenciar as relações hierárqui-

3 Bolognini baseia-se, sobretudo, em Eni P. ORLANDi (1988; 1990 e 1993). 
cas de poder que existem entre o Brasil e a Alemanha ${ }^{4}$ desde os inícios da colonização européia até hoje ${ }^{5}$.

BoLOGNINI parte do pressuposto de que "os lugares de interlocução" - isto é, as imagens que dois sujeitos fazem "de seu próprio lugar e do lugar do outro" (PÊCHEUX 1990: 82) - que marcam as relações entre brasileiros e alemães até hoje estão marcadas pela história das relações entre esses dois países (Bolognini 1996: 22). Ao se descrever a Alemanha apenas como berço de grandes realizações culturais (1996: 172), como um país desenvolvido, com tecnologia avançada, cujos produtos são objetos de consumo de outros países (1996: 141), ou como um lugar onde os conflitos, quando surgem, são sempre resolvidos (1996: 177) - como acontece no material didático analisado por BologNINI -, contribuir-se-ia para estabilizar discursos e imaginários produzidos durante os últimos séculos em favor da manutenção de uma suposta posição superior da Europa frente ao Brasil. Tal discurso sugeriria, conforme defende Bolognini, uma postura ideológica que acabaria reforçando o lugar de interlocução supostamente inferior do brasileiro em relação ao alemão.

A argumentação de BoLOGNINI certamente corrobora aquela de SousA, mencionada acima, que aponta a hierarquização que marca o imaginário acerca da Alemanha e do Brasil. Um exemplo, que pode aqui ilustrar a persistência desse imaginário marcado pelo discurso colonial acerca do Brasil em material didático atualmente utilizado no ensino de alemão, é uma passagem de Die Suche (Textbuch 2), na qual uma personagem brasileira, que ocupa um lugar importante na história que guia todo o livro, é apresentada como uma mulher especialmente bonita - parecendo uma "fada, uma princesa" (2002: 36) - cuja marca mais característica seria, conforme ela mesma

4 Bolognini refere-se exclusivamente à Alemanha, mas entendemos que a mesma argumentação poderia ser desenvolvida em relação aos outros países de língua alemã, isto é, a Áustria e a Suíça.

5 O fato de a Alemanha, a Áustria e a Suíça não terem participado ativamente na colonização do Brasil não significa que o discurso dominante nesses países não tenha incorporado as características geralmente associadas ao discurso colonial. Para discussões mais aprofundadas sobre esse tema, cf., por exemplo, Ana Maria de M. Belluzzo (2000) e Celeste H. M. R. de Sousa (1996). 
explica, um papagaio que leva nas costas (2002: 15). Herdeira de seu padrasto milionário, ela é acompanhada por um senhor vestido num estilo que lembra os filmes sobre a época colonial (2002: 37). Além disso, a personagem é apresentada como filha de uma brasileira "de nome Maria" (2002: 47) que, quando jovem, era uma "moça muito linda" (2002: 47) que teve um romance amoroso, uma "aventura de férias", (2002: 15) com um alemão que a conquistou por ser "alto, esbelto" e por saber dançar samba "fantasticamente" (2002: 47). No mesmo livro, a personagem principal, o alemão Helmut Schmidt, destaca que associa com o Brasil apenas palavras como "samba", "carnaval", "favelas" e a "floresta da Amazônia" (2002: 36). Como já indicam essas poucas citações, o referido material didático sugere uma interpretação que estabiliza certos efeitos de sentido que têm norteado a história sobre o Brasil escrita por europeus. Ou seja, os brasileiros são caracterizados, na maioria das vezes, por uma grande sensualidade, por sua liberdade sexual e pelo estreito contato com a natureza exótica do seu país, enquanto este permanece reduzido à exuberância dessa natureza. Cultural, social e economicamente, o Brasil aparece numa posição inferior àquela da Europa. Essa imagem não é nem contestada, nem problematizada, pelo discurso apresentado no material didático Die Suche.

A representação de uma personagem brasileira em um livro didático de alemão constitui uma exceção. Isso se deve, certamente, ao fato de ainda quase não existir produção no Brasil de material didático para o ensino do alemão como língua estrangeira ${ }^{6}$. Talvez um material produzido aqui pudesse enfocar mais criticamente as especificidades dos possíveis contatos entre as duas culturas. Sem pretender sugerir que essas especificidades possam - ou devam - ser discutidas exaustivamente ou exclusivamente em sala de aula, seria, no entanto, certamente possível sensibilizar um pouco mais os aprendizes para esse tema. A omissão de discussões sobre aspectos como a persistência de resíduos do discurso colonial nos discursos e imaginários atuais no âmbito do ensino da língua alemã serviria apenas para mantê-los.

6 Existe o material didático "Alemão para brasileiros", da autoria de Herbert Andreas WELKER (1989), que se dirige especificamente a aprendizes brasileiros. Este material é orientado pelo progresso gramatical e não pretende estimular os aprendizes a desenvolver uma postura crítica acerca do universo da língua alemã. 
Se o exemplo citado do livro Die Suche serve para corroborar a argumentação de que o discurso de hierarquização de culturas pode ser encontrado em livros didáticos para o ensino de alemão, em outros livros didáticos percebe-se claramente o interesse dos autores em divulgar um discurso "politicamente correto". Isso pode ser ilustrado com o terceiro volume do Stufen em que duas das personagens principais são, respectivamente, uma turca e um nigeriano - ou seja, o livro dá destaque a duas culturas que, de acordo com o discurso colonial tradicional, seriam consideradas "inferiores". Os temas abordados nesse material didático - o preconceito, o racismo, o lugar dos deficientes físicos na sociedade alemã - também evidenciam o interesse em que o espaço do outro seja reconhecido.

No Stufen International, as personagens estrangeiras são apresentadas como interlocutores que ocupam um "lugar de interlocução" igual ao dos alemães com os quais têm contato. Nas amizades entre alemães e estrangeiros não há conflito, nem confrontos, e quando as diferenças aparecem, elas são solucionadas pacificamente. À guisa de exemplo, pode-se mencionar que o tema da presença de estrangeiros na Alemanha recebe o nome de "convivência internacional" (Stufen International I: Lektion 9). Na abordagem desse tema, a intolerância e os preconceitos são enfocados criticamente (Stufen International III: Lektion 23, 25) ${ }^{7}$, mas, ao mesmo tempo, os dois personagens estrangeiros - o nigeriano e a turca - declaram nunca ter tido problemas com racismo (Stufen International III: Lektion 25). Em Moment Mal, personagens estrangeiros referem-se à "intolerância", ou aos "malentendimentos", que sofrem, mas novamente são as iniciativas multiculturais existentes nos países de língua alemã que merecem o maior destaque (Moment Mal II: Lektion 24). Quando há uma história conflituosa, em que os preconceitos levam à morte de alguns habitantes de um país - algo que ocorreu algumas vezes na Alemanha nos anos 90 -, os personagens são animais (lobos e coelhos) e o lugar não é identificado (cf. Stufen International III: 80).

A partir do que foi exposto, pode-se supor que, em livros como Stufen International ou Moment Mal, o interesse em tematizar o outro não vai além de uma tentativa de homogeneizá-lo. Nesses textos, as personagens estrangeiras convivem entre os alemães como iguais e o domínio da língua alemã

7 Cf. também Moment Mal II, Lektion 24. 
é apresentado como um "traço de união" (Grigoletto 2003: 358) suficiente. Além disso, qualquer tipo de preconceito é duramente criticado. A maneira como a crítica é feita, no entanto, não abre espaço para uma discussão sobre as diferenças culturais, apenas favorece a idéia de que, no fundo, todos são iguais, de que não há diferenças entre pessoas, culturas, línguas. Ou seja, identifica-se aqui a universalização dos valores e dos pontos de vista, já que nenhum tipo de divergência, diferença ou problema entre os representantes das diversas culturas é apontado. Estes só existiriam entre os coelhos e os lobos. Essa universalização permite novamente a hipótese de que, em vez de contribuir para se refletir criticamente sobre eventuais resíduos do pensamento colonial, o material didático, muitas vezes, ajuda manter os imaginários que têm suas raízes exatamente na ideologia colonial.

Num artigo que trata de material didático de inglês produzido no Brasil, GRigOLETTO chega a uma conclusão que me parece bastante pertinente também em relação ao material didático de alemão aqui abordado. A autora defende que seria possível "conceber um livro didático que não apagasse o sentido da criação social e cultural da identidade e da diferença", em vez de apresentar representações de "identidades fixas e pretensamente não marcadas pela diferença” (2003: 360) que levam os aprendizes a se identificarem "com o discurso da igualdade, da neutralidade e da conviviência harmônica" e a se "'encaixar[em]' na cultura da outra cultura, em vez de olhá-la contrastivamente" (2003: 360). Olhar a língua estrangeira a partir do lugar do brasileiro seria uma perspectiva que "facilitaria a reflexão sobre contrastes e semelhanças entre os povos e as línguas" (GRIgOlETto 2003: 360), em vez de estabilizar a visão de uma suposta hierarquia ou igualdade total entre eles. Ainda conforme GrigoletTo (2003: 360-361), muitos livros didáticos apagam

a possibilidade de reflexão sobre a diversidade (no interior de culturas), a diferença (o outro com aquilo que eu não sou) e a especificidade [...]. Por conseguinte, escamoteiam-se os conflitos e as diferenças e a possibilidade de questionamento de produção social desses mesmos conflitos e diferenças no interior de relações de poder. O livro didático perde a chance de se constituir em instrumento de sdas construções da identidade e diferença culturais e de abertura para uma relação 
mais rica com o outro, em que não haveria a pretensão de reduzir o um e o outro em um só ser; uma relação em que a identidade e a diferença permanecessem irredutíveis uma à outra e assim fossem vivenciadas.

\section{Conclusão}

Nosso intuito aqui não é exigir que os materiais didáticos atualmente utilizados para o ensino de alemão como língua estrangeira no Brasil mudem de foco teórico ou temático - já que não são produzidos para o público do qual tratamos neste trabalho. Mas, argumentamos que não há, no Brasil, material didático publicado que leve em consideração as questões aqui levantadas em relação aos imaginários existentes acerca da língua e da cultura alemãs - que, no nosso entender, podem ser relevantes e interessantes para os aprendizes dessa língua. Assim, sem pretender desacreditar o valor didático e informativo de livros atualmente utilizados no ensino de alemão no Brasil, mas considerando o que foi exposto, parece ser possível argumentar que, atualmente, não existe um material que possa oferecer - aos aprendizes e professores interessados - uma base consistente para se refletir criticamente sobre os diversos contextos ideológicos e imagológicos que, ao longo da história de contatos entre o Brasil e a Europa, têm marcado, e ainda marcam, qualquer relação entre um brasileiro e um alemão/austría$\mathrm{co} /$ suíço $^{8}$. Sem dúvida, qualquer professor terá sempre a possibilidade de instigar os aprendizes a desenvolverem uma postura mais crítica ${ }^{9}-$ independentemente do material didático utilizado em sala de aula -, mas os livros didáticos importados não sugerem tal leitura.

8 O único material didático para o ensino de alemão como língua estrangeira publicado no Brasil segue a metodologia estruturalista e não aborda, explicitamente, as especificidades extralingüísticas do contato entre brasileiros e alemães / austrícos / suíços (RAUTZENBERG \& RAUTZENBERG 1978).

9 Não se deve ignorar que existe material didático para o ensino de alemão como língua estrangeira que coloca em xeque o imaginário ufanista acerca da Alemanha como, por exemplo, a série de vídeos "Bildschirm". Porém, esse material não é concebido como base para um curso de alemão, mas apenas como material adicional. 
Visto que no contexto do pós-colonialismo - cujas discussões inspiram, entre outras disciplinas, a Lingüística Aplicada Crítica - os esforços das pessoas de países que foram colonizados se dirigem, cada vez mais, contra os resíduos do discurso colonial, justificar-se-ia certamente a intensificação de um discurso didático e institucional que compartilhe essa postura ideológica e que possa estimular o aprendiz - e o professor - brasileiro a pensar a língua e a cultura alemã a partir do lugar de um brasileiro. Não se trata de se buscar uma "verdade" alternativa, mas sim a possibilidade de um olhar mais crítico em relação aos discursos, ideologias e imaginários que permeiam as relações entre pessoas, culturas e línguas.

\section{Referências Bibliográficas}

BAUER, Ulrich. "Ist Deutsch eine "schwere" Sprache? Linguistische Bemerkungen zur typologischen Distanz Deutsch-Spanisch und der vorwissenschaftlichen Beurteilung des Deutschen". In: $D A F-$ Brücke, Jahrgang 5/2003, Heft 5, 4-7.

Belluzzo, Ana Maria de Moraes. O Brasil dos viajantes. São Paulo, Metalivros e Objetiva 2000.

Bolognini, Carmen Zink. O lugar de interlocução de brasileiros e alemães na história de suas relações de contato (Tese de Doutorado). Instituto de Estudos da Linguagem, Campinas / SP, Universidade Estadual de Campinas 1996.

Eagelton, Terry. Ideologia: uma introdução (Tradução de Luís Carlos Borges e Silvana Vieira). São Paulo, Unesp/Bomtempo 1997.

Fairclough, Norman. Discourse and social change. Oxford, Polity Press 1995.

Grigoletto, Marisa. "O discurso do livro didático de língua inglesa: representações e construção de identidades”. In: CoRAcini, Maria José R. J. (org.). Identidade e discurso: (des)construindo subjetividades. Campinas, SP, Unicamp 2003, 351-362.

Orlandi, Eni Pulcinelli. As formas do silêncio. Campinas/SP, Unicamp 1993.

OrLANDI, Eni Pulcinelli. Terra à vista!: discurso do confronto: velho e novo mundo. São Paulo, Cortez; Campinas, SP, Unicamp 1990. 
Orlandi, Eni Pulcinelli. Discurso e leitura. São Paulo, Cortez/Campinas, SP, Unicamp 1988.

PÊCHeux, Michel. "Análise automática do discurso". In: GADET, François e Tony HaK. Por uma análise automática do discurso: uma introdução à obra de Michel Pêcheux (Tradução de Bethania S. Mariani et al.) Campinas, Unicamp 1990.

Pennycook, Alastair. "Lingüística aplicada pós-ocidental". In: Coracini, Maria José R. J. e Ernesto Sérgio BERTOLDo (org.). O desejo da teoria e a contingência da prática: discursos sobre e na sala de aula: língua materna e língua estrangeira. Campinas/SP, Mercado de Letras 2003, 21-60.

Pennycook, Alastair. "Introduction: Critical Approaches to TESOL". In: Tesol Quarterly, vol. 33, no. 3, 1999, 329-348.

Rajagopalan, Kanavillil. Por uma lingüistica crítica: linguagem, identidade e a questão ética. São Paulo, Parábola Editorial 2003.

Rautzenberg, Anke e Jörg Rautzenberg. Aufbaukurs Deutsch ( $2^{\mathrm{a}}$ ed.). São Paulo, Pedagógica e Universitária Ltda 1978.

Sousa, Celeste H. M. Ribeiro de. Retratos do Brasil: Hetero-imagens literárias alemãs. São Paulo, Arte \& Cultura 1996.

TAVAres, Luciano Lima. "Alemanha em questão. O que pensam estudantes universitários no Rio de Janeiro sobre a Alemanha, os alemães e a língua alemã". In: Anais (do) IV Congresso brasileiro de professores de alemão, Curitiba, 27/07 a 30/07, 1999. Curitiba, ABRAPA 2000, 523-528.

TwaIn, Mark. Bummel durch Europa (Tradução de Ana Maria Brock). Berlin/ Weimar, Aufbau-Verlag 1985.

Welker, Herbert Andreas. Deutsch für Brasilianer - Alemão para brasileiros. Brasília, Editora da Universidade de Brasília (Série Textos Universitários) 1989.

\section{Materiais didáticos citados no texto}

AufDERSTRASSE, Hartmut et al. Delfin: Lehrwerk für Deutsch als Fremdsprache. Ismaning, Max Hueber 2002. 
\%o Aufderstrasse, Hartmut et al. Themen Neu. Ismaning, Max Hueber 2000.

$\vec{F}$ Boon, Rüdiger van den et al. Bildschirm: Beispiele aus deutschen Fernsehsendungen. Bonn, Inter Nationes 1997.

DallapiazZA, Rosa-Maria et al. Tangram Aktuell: Deutsch als Fremdsprache. Ismaning, Max Hueber 2004.

I Eismann, V. et al. Die Suche: das andere Lehrwerk für Deutsch als Fremdsprache. Berlin/ München, Langenscheidt 2002.

$\stackrel{\Xi}{~}$ Funk, Hermann und Michael KoENIG. Eurolingua Deutsch. Berlin, Cornelsen 은. Verlag 1996.

气 MüLLER, Martin et al. Moment Mal! Lehrwerk für Deutsch als Fremdsprache. ‡ Berlin/München, Langenscheidt 1996.

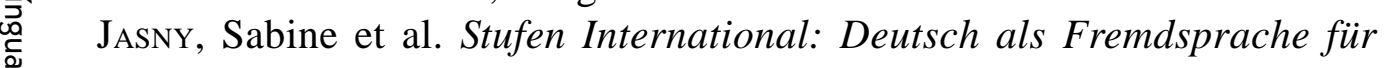
Jugendliche und Erwachsene. Stuttgart, Klett International 1995. 